\title{
When does recurrent connectivity improve neural population coding?
}

\author{
Joel Zylberberg ${ }^{1 *}$, Eric Shea-Brown $n^{1,2}$ \\ From The Twenty Third Annual Computational Neuroscience Meeting: CNS*2014 \\ Québec City, Canada. 26-31 July 2014
}

Neural systems contain many cells, and an important problem is to understand if and how those neurons work together to form a functioning system. In sensory neuroscience - which is our focus - this function is to encode information about a stimulus so that it can be transmitted to other brain areas. An experimentally accessible, and hence popular, way to assess collective behavior is to measure the trial-to-trial covariability in the responses of multiple neurons over repeats of the same stimulus, called noise correlations. Repeat presentations of the same stimulus yield different responses on each trial, and that variability is typically correlated across different neurons [1,2] (although, see [3] for one counterexample).

In the past two decades, the impact of these noise correlations on population coding has generated great interest. While nothing can add more information about the stimulus than was contained in the inputs (the data processing inequality), noise correlations determine the extent to which noise in the neural system degrades the amount of information that a neural population conveys about a stimulus (for example, see [4-6]).

There are two main ways in which these noise correlations can be generated: the cells may receive common (noisy) input from (some of) the same upstream source(s), or the cells may be (recurrently) coupled to one another. At the same time, most work on noise correlations and population coding (with a few notable exceptions, including $[7,8])$ ignores their mechanistic origins. Interestingly, the few studies that have considered the mechanistic origins of noise correlations $[7,8]$ have concluded that recurrent connectivity tends to hinder population coding, or has little overall effect: even though recurrent coupling

\footnotetext{
* Correspondence: joelzy@uw.edu

'Department of Applied Mathematics, University of Washington, Seattle, WA 98195, USA

Full list of author information is available at the end of the article
}

can "sharpen" neural tuning curves, this advantage is more than offset by the fact that it generates harmful noise correlations. This begs the question of when - if ever - recurrent coupling can improve population coding, and of whether noise correlations with different mechanistic origins have different impacts on coding performance?

To address these issues, we are investigating models in which groups of cells with, and without, recurrent coupling are driven by noisy inputs. The cells themselves are then noisy spike generators, and we are varying the fraction of shared inputs to the cells (which modifies the noise correlations due to common input), and the interneuronal connectivity, and computing the coding capacity of the resultant networks. Preliminary results indicate that, in some cases - similar to those discussed in [9] recurrent coupling can combat the cell-intrinsic variabililty enough that the population's coding performance is improved even though the noise correlations the are generated by that coupling do themselves hinder that coding performance. We are in the process of expanding and generalizing on this work.

Support for this work came from NSF grants DMS1122106, and CRCNS DMS-1208027 and a BurroughsWellcome Fund Career Award at the Scientific Interface to ESB.

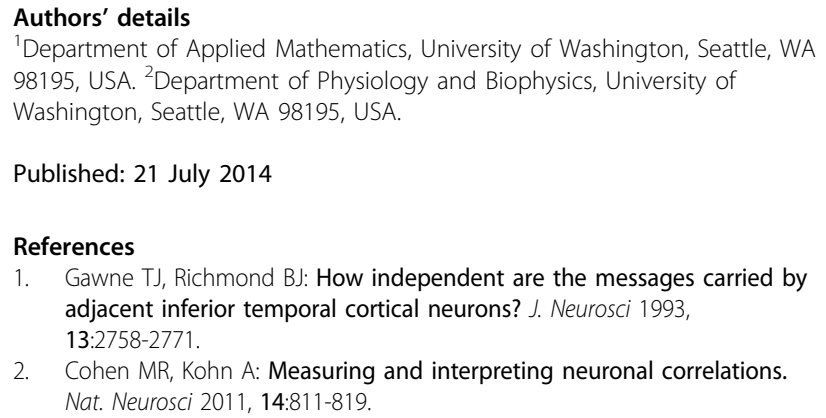

Published: 21 July 2014

\section{References}

1. Gawne TJ, Richmond BJ: How independent are the messages carried by adjacent inferior temporal cortical neurons? J. Neurosci 1993, 13:2758-2771.

2. Cohen MR, Kohn A: Measuring and interpreting neuronal correlations. Nat. Neurosci 2011, 14:811-819. 
3. Ecker AS, Berens $P$, Keliris GA, Bethge $M$, Logothetis NK, Tolias AS: Decorrelated neuronal firing in cortical microcircuits. Science 2010, 327:584-587.

4. Zohary E, Shadlen MN, Newsome WT: Correlated neuronal discharge rate and its implications for psychophysical performance. Nature 1994, 370:140-143.

5. Averbeck BB, Latham PE, Pouget A: Neural correlations, population coding and computation. Nat. Rev. Neurosci 2006, 7:358-366.

6. Hu Y, Zylberberg J, Shea-Brown E: The sign rule and beyond: boundary effects, flexibility, and noise correlations in neural population codes. PLoS Comput. Biol 2014, to appear.

7. Series $P$, Latham $P E$, Pouget $A$ : Tuning curve sharpening for orientation selectivity: coding efficiency and the impact of correlations. Nat. Neurosci 2004, 7:1129-1135.

8. Beck J, Bejjanki VR, Pouget A: Insights from a simple expression for linear Fisher information in a recurrently connected population of spiking neurons. Neural Comput 2011, 23:1484-1502.

9. Tkacik J, Prentice JS, Balasubramanian V, Schneidman E: Optimal population coding by noisy spiking neurons. PNAS 2010, 107:14419-14424.

doi:10.1186/1471-2202-15-S1-P49

Cite this article as: Zylberberg and Shea-Brown: When does recurrent connectivity improve neural population coding? BMC Neuroscience 2014 15(Suppl 1):P49.

\section{Submit your next manuscript to BioMed Central and take full advantage of:}

- Convenient online submission

- Thorough peer review

- No space constraints or color figure charges

- Immediate publication on acceptance

- Inclusion in PubMed, CAS, Scopus and Google Scholar

- Research which is freely available for redistribution

Submit your manuscript at www.biomedcentral.com/submit 